\title{
THE TIME SEQUENCE OF OVUM MATURATION IN THE RAT
}

\author{
A. TSAFRIRI AND P. F. KRAICER* \\ Biodynamics Department, Weizmann Institute of Science, Rehovot, Israel
}

(Received 28th April 1971, accepted 29th Fuly 1971)

\begin{abstract}
Summary. Follicular oocytes were examined at various times preceding ovulation. The timing of the preovulatory changes was established in relation to the 'critical period' and to ovulation time. The earliest detectable change in the oocyte, loss of the germinal vesicle and the nucleolus, occurred about $2 \mathrm{hr}$ after the presumed time of LH release, or about $9 \mathrm{hr}$ before ovulation. The first polar body was extruded about $4 \mathrm{hr}$ before ovulation. The morphology of the dictyate oocyte as revealed by interference contrast microscopy is described.
\end{abstract}

\section{INTRODUGTION}

The first meiotic division of the oocyte begins in the embryonic ovary and proceeds only to the diplotene stage of the meiotic prophase. Further development, commencing with diakinesis, only takes place before ovulation. The resting stage, in the interval between diplotene and diakinesis, is called the dictyotene or the dictyate state. Its nucleus has a special form, referred to as the germinal vesicle.

A surge of secretion of $\mathrm{LH}$ (for the purpose of this paper, LH is assumed to be the ovulation-inducing hormone in the rat) is recognized to represent the first stimulus for ovulation. This preovulatory secretion of LH is preceded by neuroendocrine events which can be blocked pharmacologically. The period during which the animal is sensitive to this pharmacological blockade is usually referred to as the 'critical period' (Everett \& Sawyer, 1950; Everett, $1961,1964)$. In the present study, the critical period was established as the time during which ovulation was blocked by administration of pentobarbitonesodium.

Following stimulation of the follicle by LH, the oocyte completes the first meiotic division and becomes a secondary oocyte. This maturation division is prerequisite to fertilization in the rat (Noyes, 1952). Previous studies of ovum maturation in the rat did not relate the timing of the changes in the ovum to the time of gonadotrophin secretion (Odor, 1955; Mandl, 1963). In this study, we have established the chronology of morphological changes with respect to the critical period and ovulation. Use of Nomarski interference microscopy (Ross, 1967; Tolansky, 1968) allowed the study to be performed on freshly isolated living oocytes. The excellent resolution, even of uncompressed oocytes, allowed

* Visiting Scientist; present address : Department of Zoology, Tel-Aviv University, Tel-Aviv, Israel. 
detailed observation of the structure of the nucleolus. The timing of the first maturation division was made using whole mounts of oocytes or squash preparations stained to demonstrate chromosomes.

\section{MATERIALS AND METHODS}

Rats obtained from the Biodynamics Institute colony were housed in a controlled environment at $25 \pm 1^{\circ} \mathrm{C}$ and approximately $50 \%$ relative humidity. Illumination was by fluorescent lamps with a lighting regimen of $14 \mathrm{hr}$ light/ $10 \mathrm{hr}$ darkness. For the convenience of the investigators, two animal rooms with different timing cycles of illumination were used, darkness being maintained either from 19.00 to 05.00 hours or from 09.00 to 19.00 hours. Vaginal smears were taken every morning between 08.00 and 10.00 hours by the same person. Analysis of a large number of vaginal smear records revealed that $70 \%$ of the rats in this colony had 4 -day cycles and $28 \%$ had 5 -day cycles. In this study, 4-day cyclic animals were used. In animals exhibiting a single 4-day cycle at a randomly chosen time, the probability of the subsequent cycle also being 4 days long was $70 \%$; after two such cycles, the probability was $94 \%$ and after three, $92 \%$. Donor rats (187), 3 to 5 months old, which had had at least two normal 4-day cycles immediately before the experimental treatment, were used here.

Rats were killed by cervical dislocation. The ovaries and, where pertinent, the ampullae of the oviducts, were excised and trimmed. The ovary was blotted and placed under a stereoscopic microscope at $\times 10$ magnification. The follicles were best visualized on a dark background; using microscissors, a small flap was cut out of the bulging follicular wall. Immediately, the tip of a polyethylene micropipette was placed into, or close to, the hole and the follicular contents were gently aspirated. The pipette was emptied into a few drops of unbuffered Ringer, $\mathrm{pH} 7 \cdot 2$, in a depression slide. Tubal ova were isolated as described by Rowlands (1942).

The oocytes were separated from débris by transfer into clean Ringer's solution. When the cumulus cells were too tightly packed to allow the oocyte to be seen clearly, they were removed by adding a few drops of $0.01 \%$ hyaluronidase (Leonard \& Kurzrock, 1945) in Ringer's solution and gently agitating. The oocytes were then mounted for microscopic examination. The mounts were $90 \mu \mathrm{m}$ thick, attained by supporting the coverglass with carefully sized glass beads. The average yield was $\mathbf{8 \cdot 3}$ oocytes from a pair of ovaries (the mode of the ovulation rate was eleven oocytes/rat). The oocytes were observed and photographed under a Nomarski interference contrast microscope (Nachet Model 300 or Zeiss Standard WL microscope). Stained squash preparations of chromosomes were made by the method of Tarkowski (1966). In the preparation of chromosome squashes from ova, $50 \%$ of the ova were lost. The chromosomes were photographed under phase contrast. Whole oocytes were fixed in alcoholic acetic acid and stained with acetic orcein (Donahue, 1968).

Timing of the critical period was established by injecting $30 \mathrm{mg} / \mathrm{kg}$ of sodium pentobarbitone at various times between 13.00 and 18.00 hours on the prooestrous day. The rats were killed the next morning and the number of oocytes in their oviducts were counted. 


\section{RESULTS}

\section{MORPHOLOGY OF PERIOVULATORY OOCYTES}

\section{Stage 1. Dictyate oocyte (Pl. 1, Figs. 1 and 2)}

The granulosa cells were closely apposed to one another and to the zona pellucida. There was no visible perivitelline space. The germinal vesicle was a sphere approximately $30 \mu \mathrm{m}$ in diameter, within which lay a large nucleolus (Pl. 1, Fig. 1). In almost all dictyate oocytes, there was an irregular body (or bodies) on the surface of the nucleolus. It was best seen in profile as one or more loops of material bulging from the surface of the nucleolus (Pl. 1, Fig. 3). When whole ova were stained for chromatin, these loops were stained intensely. The stained chromatin appeared in the shape of an envelope around the nucleolus. Thickenings and holes were seen in the stained chromatin. The shape of these thickenings recalled the bulging loops of material lying on the surface of the nucleolus of living ova (Pl. 2, Fig. 4). The presence of a chromatin coating of non-uniform structure on the nucleolus is consistent with the observations of Austin and his co-workers (Austin \& Braden, 1953; Braden \& Austin, 1953; Austin \& Bishop, 1959; Austin, 1961) as well as our own in living ova.

Within $91 \%$ of nucleoli, one or more spherical inclusions were seen (Pl. 1, Figs. 1 and 3 ). In our material, $53 \%$ of the vesicular oocytes had one such inclusion and $20 \%$ contained three or more. Neither the chromatin nor the nucleolar inclusions underwent any morphological change with the approach of the first maturation division. Thus, aside from disappearance of the nucleolus, LH appears to have no effect on its fine structure.

About $15 \%$ of oocytes in which nucleoli were seen had no germinal vesicles, even before the end of the critical period. It is quite possible that some germinal vesicle membranes were broken due to handling or following hyaluronidase treatment. Thus, in Table 1, oocytes classified as dictyate include those without distinct germinal vesicle membrane but with nucleoli.

Five exceptional dictyate oocytes were noted in our series of approximately 2000: one with two germinal vesicles, only one of which contained a nucleolus, and four with two nucleoli.

\section{Stage 2. Polar body emission}

At the time of polar body extrusion, the ooplasm contracted, leaving a perivitelline space between the oolemma and zona pellucida. No nuclear structures were seen in the interference contrast microsocope.

By staining the ova, it was possible to visualize their chromosomes ( $\mathrm{Pl}$. 2, Fig. 5). Squash preparations are preferable for analysis of the chromosomes (Pl. 2, Figs. 6 and 7) and allow accurate timing of the first reduction division. All ova stained before 22.00 hours had tetrads. From this time until 24.00 hours, the tetrads divided giving rise to dyads and polar bodies. After 24.00 hours, all ova had dyads (Pl. 2, Fig. 7 and Text-fig. 1).

A few ova with bulges at the site of presumptive polar body extrusion were also classified as Stage 2. Their relative rarity implies that the extrusion of the polar body is a rapid process. 
TABLE 1

TIMING OF CHANGES IN OOGYTE MORPHOLOGY AND OF OVULATION

\begin{tabular}{|c|c|c|c|c|c|c|}
\hline $\begin{array}{l}\text { Period of } \\
\text { isolation } \\
\text { (hours) }\end{array}$ & $D O$ & $\begin{array}{l}\% \text { in } \\
\text { maturati } \\
\mathcal{N N}\end{array}$ & $\begin{array}{l}\text { arious } \\
n \text { stages } \\
P B_{1}\end{array}$ & ${ }^{s}{ }_{v}$ & $\begin{array}{l}\text { No. of } \\
\text { oocytes } \\
\text { isolated }\end{array}$ & $\begin{array}{c}\text { No. of } \\
\text { donor rats }\end{array}$ \\
\hline $\begin{array}{l}08.00 \text { to } 09.00 \\
09.00 \text { to } 10.00 \\
10.00 \text { to } 11.00 \\
11.00 \text { to } 12.00 \\
12.00 \text { to } 13.00 \\
13.00 \text { to } 14.00 \\
14.00 \text { to } 15.00 \\
15.00 \text { to } 16.00 \\
16.00 \text { to } 17.00 \\
17.00 \text { to } 18.00 \\
18.00 \text { to } 19.00 \\
19.00 \text { to } 20.00 \\
20.00 \text { to } 21.00 \\
21.00 \text { to } 22.00 \\
22.00 \text { to } 23.00 \\
23.00 \text { to } 24.00 \\
24.00 \text { to } 01.00 \\
01.00 \text { to } 02.00 \\
02.00 \text { to } 03.00 \\
03.00 \text { to } 04.00 \\
04.00 \text { to } 05.00 \\
05.00 \text { to } 06.00\end{array}$ & $\begin{array}{l}97(16) \\
96(11) \\
94(15) \\
97(23) \\
95(11) \\
96(21) \\
96(17) \\
94(8) \\
92(29) \\
59(18) \\
48(16) \\
26(11) \\
4(3) \\
19 \\
2 \\
15(11) \\
4 \\
9(5) \\
4(3) \\
8(6) \\
2(2) \\
-\end{array}$ & $\begin{array}{r}3 \\
6 \\
3 \\
5 \\
3 \\
3 \\
4 \\
8 \\
39 \\
52 \\
72 \\
94 \\
81 \\
73 \\
39 \\
33 \\
32 \\
28 \\
10 \\
5 \\
1\end{array}$ & $\begin{array}{l}\overline{4} \\
\overline{-} \\
\overline{-} \\
1 \\
1 \\
\frac{2}{2} \\
\overline{2} \\
2 \\
\frac{25}{46} \\
63 \\
59 \\
59 \\
20 \\
11 \\
-\end{array}$ & $\begin{array}{l}= \\
= \\
= \\
= \\
= \\
= \\
= \\
= \\
= \\
= \\
= \\
\bar{Z} \\
10(4) \\
61(35) \\
82(16) \\
99(30)\end{array}$ & $\begin{array}{r}37 \\
26 \\
47 \\
66 \\
38 \\
68 \\
70 \\
63 \\
51 \\
51 \\
96 \\
81 \\
109 \\
67 \\
53 \\
46 \\
78 \\
97 \\
101 \\
116 \\
120 \\
93\end{array}$ & $\begin{array}{r}5 \\
5 \\
6 \\
7 \\
5 \\
11 \\
9 \\
9 \\
7 \\
7 \\
11 \\
10 \\
11 \\
9 \\
6 \\
5 \\
7 \\
10 \\
11 \\
15 \\
12 \\
9\end{array}$ \\
\hline
\end{tabular}

DO: Dictyate oocytes (number in parentheses is the \% lacking germinal vesicle but with nucleolus). NN: No visible nuclear structures. PB $_{1}$ : First polar body seen. Ov: Ovulated oocytes (number in parentheses indicates $\%$ with first polar body still present).

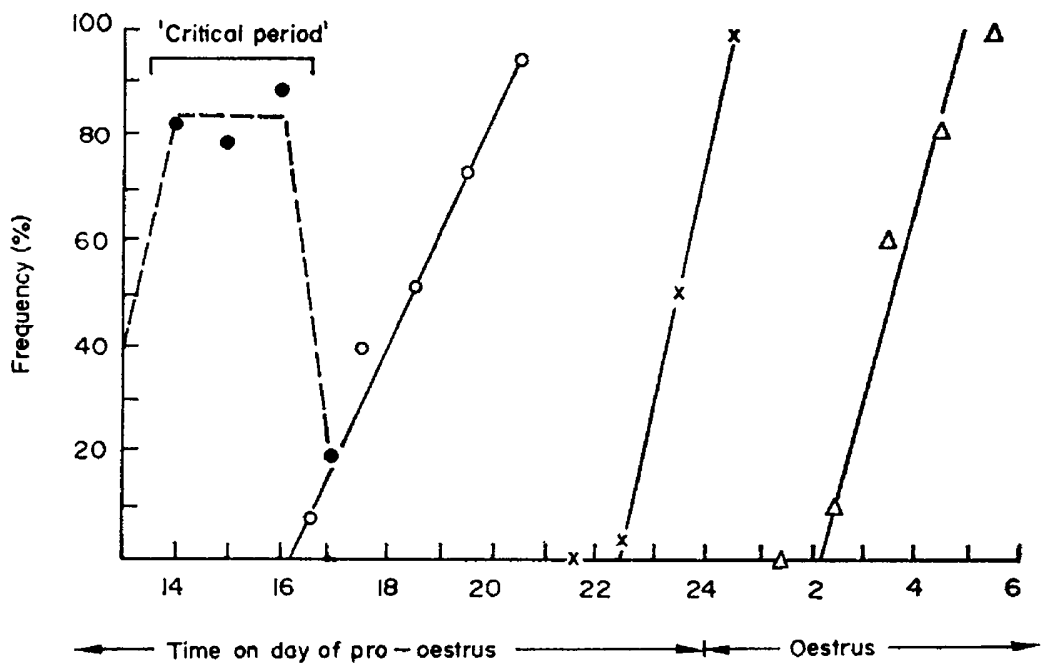

Text-Fig. 1. The relation between 'critical period' and the timing of maturation changes in the preovulatory rat oocyte: 9 , block of ovulation by Nembutal administration; 0 , disappearance of the germinal vesicle and nucleolus and onset of meiotic metaphase; $x$, appearance of dyads; $\Delta$, ovulation. 

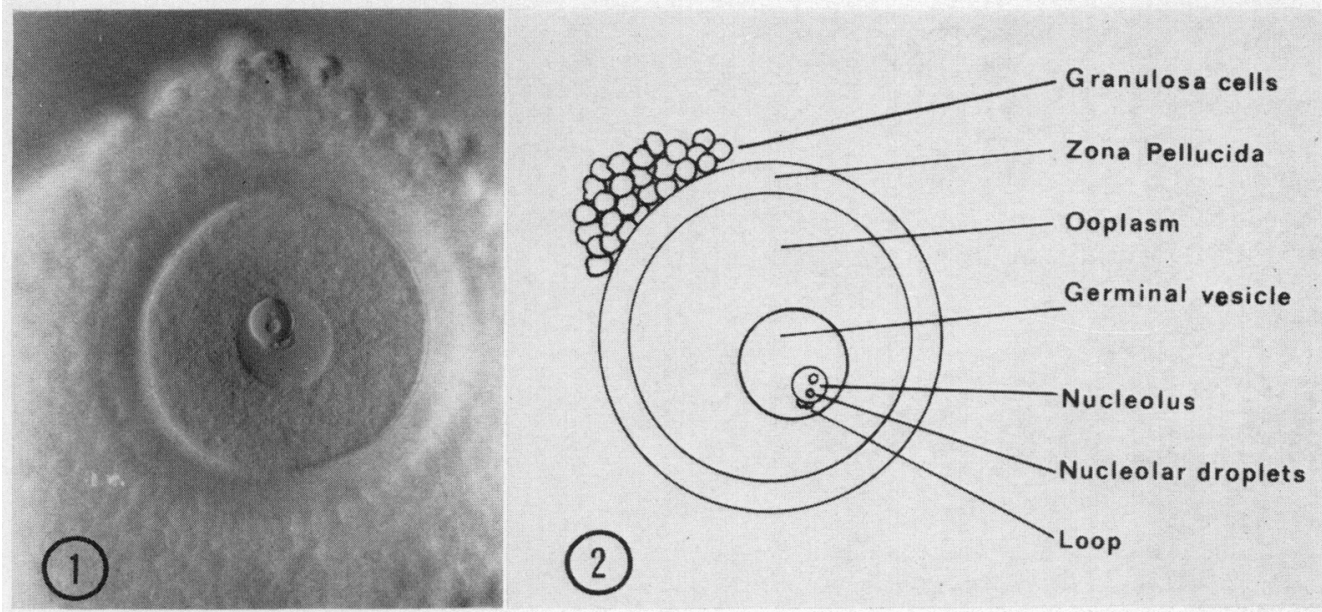

firs. 1. Photograph of a dictyate oocyte by interlerence contrast microscopy. $\times 320$. firc. 2. Diagram of the parts of a vesicular oocyte.

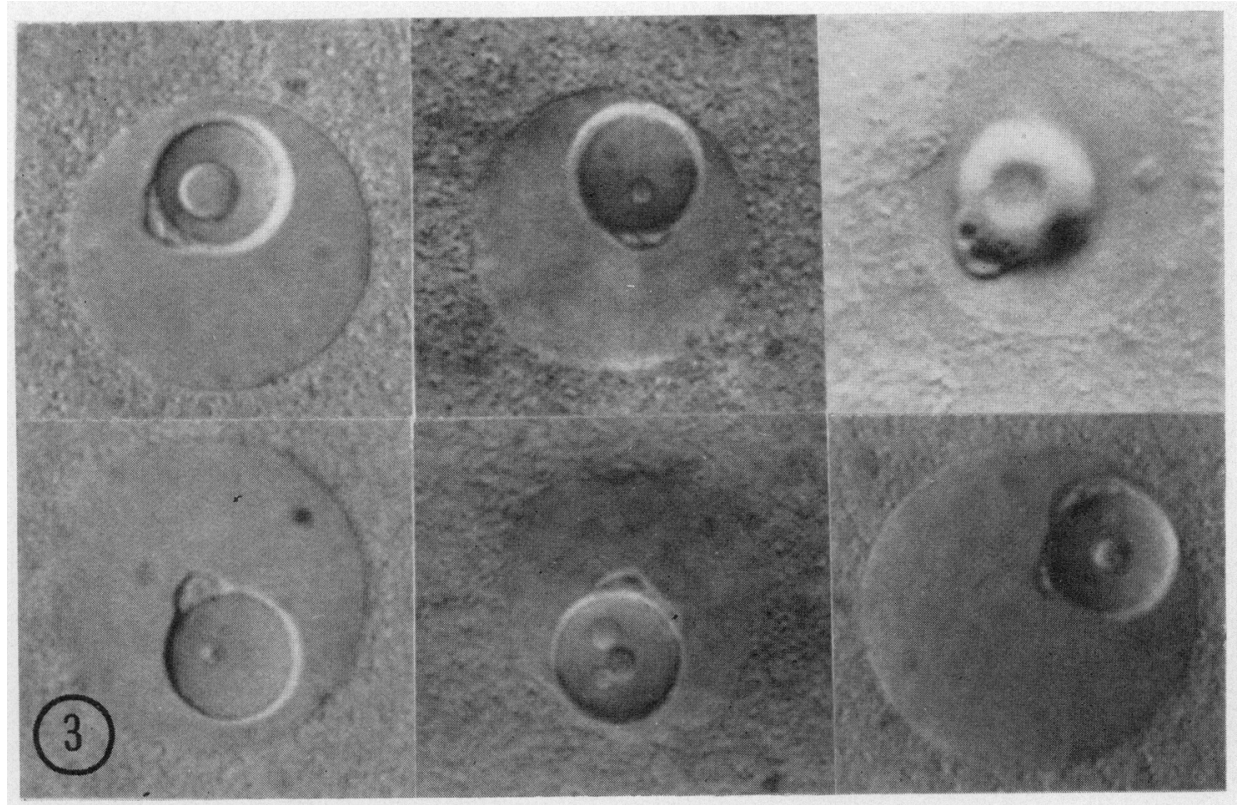

lig. 3. Geminal vesicles showing intranuclcolar inclusion droplets and loops of chromatin $\times 800$. 


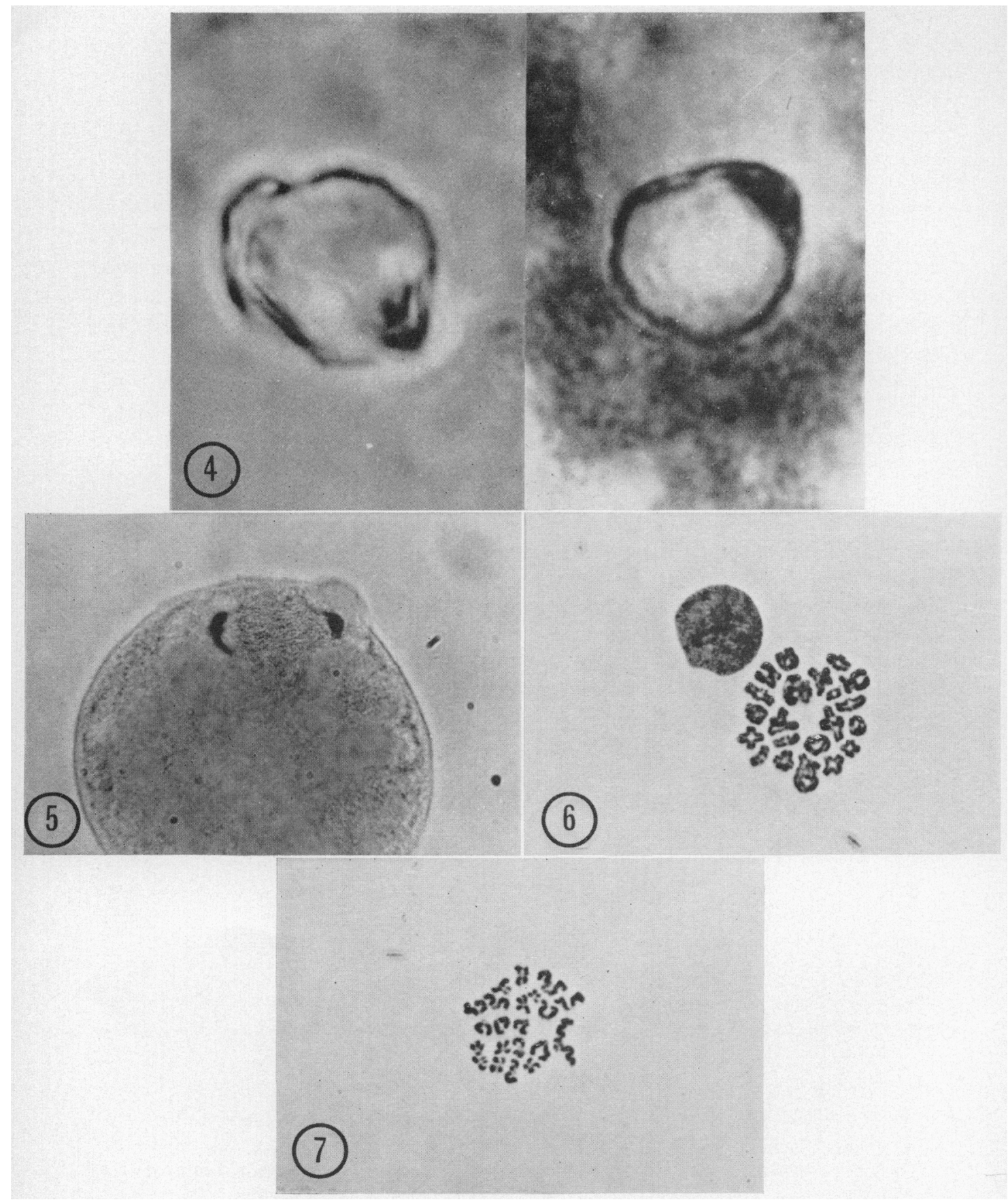

Fig. 4. Nucleoli after staining of chromatin. Phase contrast, $\times 2000$.

FIG. 5. Stained whole ovum showing polar body extrusion. Phase contrast, $\times 1800$.

Fig. 6. Tetrads. A granulosa-cell nucleus is also seen. Phase contrast, $\times 2200$.

Fig. 7. Dyads. Phase contrast, $\times 2200$.

(Facing p. 391) 
Stage 3. Secondary oocyte

The presence of the first polar body indicates completion of the first meiotic division. However, since the first polar body is not stable, the time of its appearance (Table 1) does not accurately reflect the timing of the first meiotic division. Squash preparations were required to define this stage.

\section{Stage 4. Ovulation}

From approximately 03.00 hours, fluid distension of the bursae ovaricae of a few rats was noted. This fluid was found to contain oocytes. These bursal ova were apparently freshly released from follicles and had not yet been swept into the oviduct. The finding of bursal oocytes between 03.00 and 05.00 hours further defined the time of ovulation. Their rarity emphasized the rapidity of the passage of ova into the infundibulum. In other rats, a few ova were found in the ampullae but no fluid distension could be seen. By 05.00 hours, all rats showed the familiar postovulatory picture of a cumulus mass in a fluid-distended ampulla (Rowlands, 1942).

\section{CHRONOLOGY OF PERIOVULATORY GHANGES}

The critical period for blockage of ovulation by pentobarbitone in our colony was 13.30 to 16.30 hours. The number of animals ovulating as a function of injection time was: 13.00 hours, $6 / 10 ; 14.00$ hours, $2 / 12 ; 15.00$ hours, $2 / 10$; 16.00 hours, $1 / 10 ; 17.00$ hours, $8 / 10$; and 18.00 hours, $7 / 9$ (Text-fig. 1 ).

The time-curve of disappearance of the germinal vesicle is shown in Text-fig. $1 ; 50 \%$ of the ova had lost their germinal vesicles at 18.30 hours on the evening of pro-oestrus, i.e. during the hour before the beginning of the dark period. The corresponding times for $10 \%$ and $90 \%$ losses were 16.30 and 20.00 hours.

Chromosomes were never seen in squash preparations made before 17.00 hours. Only seven sets of tetrads were recovered from twenty-one ova examined between 17.00 and 18.00 hours. This low recovery suggested that condensation of tetrads began at 17.00 hours, $1 \mathrm{hr}$ before the median time of germinal vesicle disappearance.

The earliest appearance of the first polar body in living ova was between 22.00 and 23.00 hours. This was also the time interval during which the first dyads were detected. Between 23.00 and 24.00 hours, $50 \%$ of the ova contained dyads and after 24.00 hours, essentially all the ova contained dyads. The time of expulsion of the first polar body must, therefore, have been very short and uniform. This was not reflected in the actual appearance of polar bodies in the follicular eggs. The proportion of secondary oocytes containing polar bodies reached a maximum of approximately $2 / 3$ (Table 1 ) and remained at this level for about $4 \mathrm{hr}$. It then fell to approximately $1 / 3$ of the ova. Polar bodies, even when partially degenerated, were easily seen; it is almost impossible that $1 / 3$ of the polar bodies would go unseen. It must, therefore, be assumed that $1 / 3$ of the polar bodies were lost almost as soon as they were formed; the others persisted for $4 \mathrm{hr}$ or more before disappearing. Ovulation began between 02.00 and 03.00 hours. By 05.00 hours, ovulation was complete. The mean time of ovulation was 03.30 hours. Thus, the time between the end of the critical period and ovulation was $11 \mathrm{hr}$. The total number of oocytes isolated was 1574 . 


\section{DISCUSSION}

In this study, the progress of the first maturation division has been followed and timed. The entire sequence of ovum maturation and ovulation was seen to occupy about $9 \mathrm{hr}$ (Text-fig. 1). The ova were examined fresh or after staining in toto by very simple methods. Details of the meiotic division were not seen as well as in histological sections (Odor, 1955; Mandl, 1963). However, examination of living ova is less tedious and the major stages of maturation are plainly seen. Also, the ova can be classified within $15 \mathrm{~min}$ of removal from the donor, an advantage when further study of the ova is desired.

The critical period is the time interval of hypothalamic activation of ovulatory LH secretion. By comparing hypophysectomy and atropine-blockade, Everett (1956) concluded that the 'stimulation and hormone release are coextensive' in the rat. More recently, it has been shown (Monroe, Rebar, Gay \& Midgley, 1969; Ayalon, Tsafriri, Lindner, Cordova \& Harell, 1972) that the peak of LH concentration in the blood, determined by immunoassay, occurs later than the end of the critical period. This apparent inconsistency probably reflects the sensitivity of follicles to less than the maximal quantities of LH which are secreted. Thus, we have shown (Tsafriri, Lindner \& Kraicer, 1970) that $50 \%$ of follicles explanted intact into hormone-free medium have been sufficiently stimulated to be 'committed' to complete meiosis by 16.00 hours, and $90 \%$ by 18.00 hours. On the basis of these results, we conclude that the end of the critical period marks the time at which an ovulatory quota of $\mathbf{L H}$ has been secreted. The interval between the end of the critical period (16.30 hours) and onset of changes in the oocytes is quite short; $50 \%$ of the oocytes have lost their germinal vesicle and nucleolus by 18.30 and $90 \%$ by 20.00 hours (Text-fig. 1 ).

It is rather strange that the first event in ovum maturation-germinal vesicle disappearance - should show a greater spread in its timing than later eventspolar body extrusion and ovulation. This suggests that the 'clock' which controls these later events is precise and shows less inter-animal variation than germinal vesicle disappearance. It appears that the time at which reorganization of chromosomes begins does not determine the time of polar body emission. Once the ovum is committed to ovulation (or atresia), i.e. has ended its dictyate phase, subsequent changes are strictly synchronized. Thus, for isolation of follicular ova at a specific stage of the preovulatory maturation, the time of collection is chosen from Text-fig. 1. Within $15 \mathrm{~min}$, ova can be isolated, cleaned of tissue débris and examined microscopically to eliminate any dictyate oocytes inadvertently isolated.

\section{ACKNOWLEDGMENTS}

Professor H. R. Lindner has given his fullest encouragement at all stages of this study. The authors gratefully acknowledge his interest and support. Mrs A. Tsafriri gave excellent technical assistance. This work was supported in part by grant M65-143 (to H.R.L.) of the Population Council, Inc. of New York and the Ford Foundation, and was carried out in partial fulfilment by one of the 
authors (A.T.) of the requirements for a Ph.D. degree from the Feinberg Graduate School of the Weizmann Institute of Science.

\section{REFERENCES}

Austin, C. R. (1961) The mammalian egg. Blackwell Scientific Publications, Oxford.

Austin, C. R. \& Bishop, M. W. H. (1959) Differential fluorescence in living rat eggs treated with acridine orange. Expl Cell Res. 17, 35.

Austiv, G. R. \& BRADEN, A. W. H. (1953) The distribution of nucleic acids in rat eggs in fertilization and early segmentation. I. Studies on living eggs by ultraviolet microscopy. Aust. F. biol. Sci. 6, 324.

Ayalon, D., Tsafriri, A., Lindner, H. R., Cordova, T. \& Harell, A. (1972) Serum gonadotrophin levels in pro-oestrous rats in relation to the resumption of meiosis by the oocytes. F. Reprod. Fert. (In press).

Braden, A. W. H. \& Austin, C. R. (1953) The distribution of nucleic acids in rat eggs in fertilization and early segmentation. II. Histochemical studies. Aust. F. biol. Sci. 6, 665 .

Donahue, R. P. (1968) Maturation of the mouse oocyte in vitro. II. Sequence and timing of nuclear progression. 7. exp. Zool. 169, 237.

EveretT, J. W. (1956) The time of release of ovulating hormone from the rat hypophysis. Endocrinology, $59,580$.

Everetr, J. W. (1961) The mammalian female reproductive cycle and its controlling mechanisms. In: Sex and Internal Secretions, 3rd edn, Vol. 1, pp. 497-555. Ed. W. C. Young. Williams \& Wilkins, Baltimore.

EvERETT, J. W. (1964) Preoptic stimulative lesions and ovulation in the rat: thresholds and LH-release time in late diestrus and proestrus. In: Major Problems in Neuroendocrinology. Eds. E. Bajusz and G. Jasmin. Karger, Basle.

EveretT, J. W. \& SAWYeR, C. H. (1950) A 24-hour periodicity in the LH-release apparatus of female rats disclosed by barbiturate sedation. Endocrinology, 47, 198.

LEONARD, S. L. \& KURZROCK, R. (1945) A study of hyaluronidase-effects on the follicle cells of ovulated rat ova. Endocrinology, $37,171$.

Mandi, A. M. (1963) Preovulatory changes in the oocyte of the adult rat. Proc. R. Soc. B, 158, 105.

Monroe, S. E., Rebar, R. W., Gay, V. L. \& Mibgley, A. R. (1969) Radioimmunoassay determination of luteinizing hormone during the estrous cycle of the rat. Endocrinology, 85, 720.

Noyes, R. W. (1952) Fertilization of follicular ova. Fert. Steril. 3, 1.

ODOR, D. L. (1955) The temporal relationship of the first maturation division of rat ova to the onset of heat. Am. F. Anat. 97, 461 .

Ross, K. F. A. (1967) Phase contrast and interference microscopy for cell biologists. Edward Arnold, London.

RowLAnds, I. W. (1942) Collection of eggs from the Fallopian tube of the rat. Nature, Lond. 150, 267.

TARKowski, A. K. (1966) An air-drying method for chromosome preparations from mouse eggs. Cytogenetics, 5, 394.

TolansKy, S. (1968) Interference microscopy for the biologist. Thomas, Springfield, Ill.

TsAfriri, A., Lindner, H. R. \& KRAICER, P. F. (1972) LH-induced meiotic division in follicle enclosed ova in culture. Proc. N.I.H. Conf. Regulation of Mammalian Reprod., Bethesda, 1970 (In press). 